\title{
Meander Conductor Shape Influence on the Electrodynamic Parameters of the Meander Structures
}

\author{
Diana Belova-Ploniene ${ }^{*}$ (PhD Student, Vilnius Gediminas Technical University, Vilnius, Lithuania), \\ Andrius Katkevičius (Professor, Vilnius Gediminas Technical University, Vilnius, Lithuania)
}

\begin{abstract}
Meander structures allow reducing the size of the microwave devices while keeping the same operational characteristics. The shape of meander makes a considerable impact on the operation of microwave devices. Therefore, the structure of meander is widely investigated nowadays. The review of different shapes of a meander conductor is presented in this article. Two models with different shape of connecting conductors are designed and discussed in detail. The influence of variation of the length and width of connecting conductors on the electrical parameters of the meander is revealed using the traditional model of meander. Later, the comparison of the traditional model and the model with rectangle-shape peripheral parts of a meander conductor is presented. The increase in the width of connecting conductors from $0.2 \mathrm{~mm}$ to $1.0 \mathrm{~mm}$ has narrowed the bandwidth by $346 \mathrm{MHz}$ until $2.388 \mathrm{GHz}$. The increase in the length of connecting conductors to $2.3 \mathrm{~mm}$ has allowed moving the stopband to higher frequencies. The usage of the rectangle-shape connecting conductors slightly reduces the pass-band but allows achieving more stable input impedance.
\end{abstract}

Keywords - Meander structures; Method of moment; Microwave devices; Modelling.

\section{INTRODUCTION}

Meander structures are very popular nowadays [1]-[3]. The popularity of meander structures is caused by the possibility of device miniaturization [4], [5]. Meander structures are used in microwave devices like antennas [6], [7], antennas arrays [8], [9], phase shifters [10], [11], filters [12], [13], resonators [14], [15], delay lines [16], [17] and others. It can be stated that meander structures are widely used in the field of Internet of Things (IoT) [18] with the greatest emphasis on small pocket devices [19].

The structure of the meander can vary greatly depending on the field of usage and it has a significant effect on the electrodynamic characteristics of the meander and the whole device.

The main constructive parameters, which have the influence on the electrodynamic parameters of the meander, are the width of the meander strips $-w$; the gap between adjacent meander strips $-s$; the length of the central part of meander electrode $L_{1}$; the length of the connecting conductor of meander $-L_{2}$; the height of the substrate $-h$ (Fig. 1). The shape of the connecting conductors has also the significant influence on the operation of the device.

The review of the different structures of meander conductors used in different applications will be presented in this paper. Moreover, the summarised information will be used for the modelling purpose.

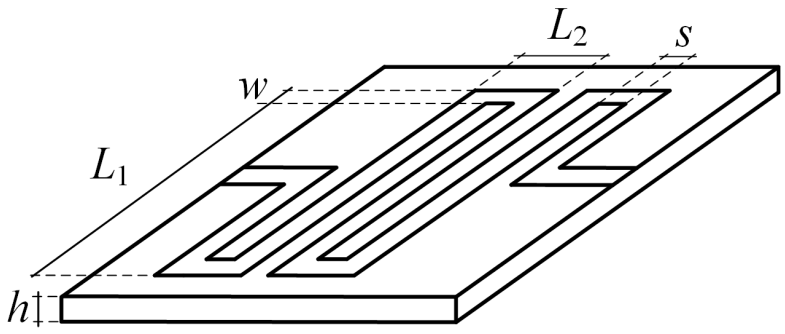

Fig. 1. Traditional meander construction where $w$ - the width of the meander strip; $s$ - the gap between adjacent meander conductors; $L_{1}$ - the length of the central part of meander conductor; $L_{2}$ - the length of the connecting conductors; $h$ - the height of the substrate.

The two different models of the traditional meander conductor and the conductor with triangle-shape peripheral parts will be presented and discussed in detail.

\section{APPLICATIONS OF MEANDER STRUCTURES}

Structures with the meander conductor are used in many different applications. More or less all the fields are concentrated in the field of microwave devices. Usually the structure and material vary a lot depending on the field of application. The review of different structures of meander depending on the field of application is presented in this subchapter.

\section{A. Antennas With Meander Structures}

One of the major fields of application of meander structures is antenna field. Miniaturized Long-Term Evolution (LTE) antenna, which has the meander structure, is presented in [20]. This antenna is capable of operating in $700 \mathrm{MHz}$ and $2600 \mathrm{MHz}$ dual-band frequencies. The antenna was miniaturized using the meander structure. The overall size of the antenna is

\footnotetext{
* Corresponding author.

E-mail: d.belova-ploniene@vgtu.lt
} 
$54 \mathrm{~mm} \times 18 \mathrm{~mm} \times 8 \mathrm{~mm}$. The substrate is made from FR4 material. The authors emphasise that changing the three parameters helped achieve the required operating frequencies. These parameters were the antenna height, substrate permittivity and the length of the ground plane. The authors used the meander structure with shields between adjacent meander strips.

The compact wideband slot antenna is presented in [21]. This antenna has a slotted $\mathrm{Y}$ shape meander structure. The connecting conductors have the same length, but the length of centre parts of the meander conductor varies. This antenna was designed for the $5 \mathrm{G} 2.6 \mathrm{GHz}$ applications. The working frequency range varies from $2.33 \mathrm{GHz}$ to $3.56 \mathrm{GHz}$. The gain was larger than $0.6 \mathrm{dBi}$. The size of the antenna was $30 \mathrm{~mm} \times 20 \mathrm{~mm}$. The FR4 material was used for the substrate.

Circular slot antenna for the satellite communications is presented in [22]. This antenna has a rectangular patch. The circular slot is formed on the patch. The meander structure is formed on the circular slot. The meander has the symmetrical structure with respect to the longitudinal axis. The length of central and peripheral parts of the meander is constant and equal to $6 \mathrm{~mm}$ and $3 \mathrm{~mm}$, respectively. The width of the meander conductor is $0.2 \mathrm{~mm}$. According to the presented figures, it looks that the gap between adjacent strips is equal to $3 \mathrm{~mm}$. Rogers 5880 material was used for the substrate. The $\varepsilon_{\mathrm{r}}=2.2$ and $\delta$ is equal to 0.0009 . The designed antenna works in two frequencies and could be used in satellite communication. The resonant frequencies of the antenna are equal to $11 \mathrm{GHz}$ and 11.9 GHz. The corresponding return losses are equal to $-26.89 \mathrm{~dB}$ and $-6.04 \mathrm{~dB}$.

The planar microstrip antenna for television white space applications is presented in [23]. This antenna works in the frequency band from $470 \mathrm{MHz}$ to $700 \mathrm{MHz}$. The meander conductor has allowed achieving lower frequency resonance in UHF band and reducing the size of antenna to $46 \mathrm{~mm} \times 46 \mathrm{~mm}$. The meander conductor has three different parts. Two parts are identical (the length is equal to $46 \mathrm{~mm}$ ) and the central meander has a lower dimension (the length of central strip is equal to 10 $\mathrm{mm}$ ). This structure can be called a hybrid structure. FR4 epoxy material was used for the substrate. The dielectric constant of substrate is equal to 4.4. The thickness of the substrate is equal to $1.6 \mathrm{~mm}$.

These are just four examples of antennas with meander conductors. Antennas work in different frequencies and are designed for different applications. Therefore, the structure of the meander conductor is also different. Summarising, it could be said that the considerable influence on the operation of devices is made by varying the length and width of central and peripheral parts of the meander conductor.

\section{B. Antennas Arrays With Meander Structures}

Structures with meander conductors are also used in antenna arrays. One of the examples could be the quadrifilar helical array antenna, which is made for the GPS applications [24]. This antenna consists of quadrifilar helical $2 \times 2$ antenna array. The antenna array is printed on the outer side of the tube. The meander structures allowed reducing the size of antenna by
$44 \%$ compared to a straight line. The working frequency range of antenna is from $1.52 \mathrm{GHz}$ to $1.66 \mathrm{GHz}$. The length of antenna is $45 \mathrm{~mm}$. The diameter of the tube is $26 \mathrm{~mm}$. The flexible Pyralux AC material was used for the substrate, which $\varepsilon_{\mathrm{r}}=3.7$ and $\tan \delta=0.0014$.

Another example of antenna array is presented in [25]. The proposed structure consists of an array of meander antennas, which are isolated one from the other by using the electromagnetic bandgaps. Each antenna is back parasiticcoupled with a rectangular patch. This type of antenna could work at frequencies of $3.48 \mathrm{GHz}$ and $4.86 \mathrm{GHz}$. The size of a parasitic rectangular patch is $18 \mathrm{~mm} \times 15 \mathrm{~mm}$. The length and the width of the whole meander conductor are $11 \mathrm{~mm} \times 9.7 \mathrm{~mm}$. The length of the central part is $9.7 \mathrm{~mm}$. The length of the connecting conductor is $1 \mathrm{~mm}$. The gap between adjutant strips is $1 \mathrm{~mm}$. The shape is symmetrical with the longitudinal axis.

Numerical analysis of the antenna array with and without meandered lines is presented in [26]. Each antenna consists of two substrate layers. Both substrates are made from the same dielectric, the permittivity of which is equal to 3.66 . The thickness of an upper substrate is equal to $0.508 \mathrm{~mm}$. The thickness of a lower substrate is equal to $0.702 \mathrm{~mm}$. Both substrates are separated by a common ground plane. The patch elements are printed on the top of the upper substrate and the feeding line is printed on the bottom of the lower substrate. The analysis has shown that meander lines have positive and negative features to the whole antenna array. The antenna with meander lines has wider bandwidth but worse return loss compared to the conventional antenna. The antenna gain and patch lobes are also worse compared to antennas with meander lines. The lower mutual coupling is the main advantage of antennas with meander structures. This means that the distance between separated antennas in the antenna array could be shorter. As a result, it will be possible to reduce the size of the entire antenna array while maintaining the same operating characteristics.

\section{Filters With Meander Structures}

An on-chip bandpass filter is presented in [27]. The centre frequency of the filter is equal to $33 \mathrm{GHz}$. The corresponding bandwidth is equal to $18 \%$. The centre frequency was selected by configuring the length of resonator of the meander line. The filter is miniaturized using two meander structures. It consists of three layers. Meander structures are placed on the top and middle layers in the opposite directions in order to generate strong resonance. The length of the meander was tuned using jumpers between two layers. The size of the entire filter is only $0.126 \mathrm{~mm} \times 0.3 \mathrm{~mm}$. Excluding the size reduction, meander structures also improved the stopband attenuation till $44 \mathrm{~dB}$. The obtained minimum insertion loss was equal to $2.6 \mathrm{~dB}$.

Another example of a compact dual-band bandpass filter is presented in [28]. The main advantages of this filter are compactness and multiband. The size of the entire filter with the substrate is $34.5 \mathrm{~mm} \times 19 \mathrm{~mm} \times 1.5 \mathrm{~mm}$. The substrate is made from Rogers RO 3206 material, relative permittivity of which is equal to 6.15 . The size of the printed rectangular resonator on the substrate is equal to $13.6 \mathrm{~mm} \times 11.08 \mathrm{~mm}$. 
Every two opposite sides of the rectangular resonator have the same structure of the meander. The both central frequencies are configured by changing the length of meanders of the opposite sides of a rectangular resonator. In this particular example, the central frequencies are equal to $2.51 \mathrm{GHz}$ (bandwidth of about $12.5 \%$ ) and $5.11 \mathrm{GHz}$ (bandwidth of about $4 \%$ ). The return loss of less than $-32 \mathrm{~dB}$ and insertion loss of about $-0.23 \mathrm{~dB}$ were obtained in the band of lower frequencies. Return loss of less than $-21 \mathrm{~dB}$ and insertion loss of about $-0.9 \mathrm{~dB}$ were obtained in the band of higher frequencies.

\section{Phase Shifters With Meander Structures}

Phase shifter is another group of microwave devices, which use the meander structures for the miniaturization purpose. Phase shifters are used for beam forming in antenna arrays. There could be many phase shifters in the antenna array; therefore, the size, range of phase shift and cost are the most important factors.

The design of tunable phase shifter is presented in [29]. This phase shifter is specified for radars and wireless communication systems. The tenability is achieved using a magnetodielectric perturber on a meander line microstrip. The tenability is controlled using a piezoelectric transducer by specifying different dc bias and changing the distance between the perturber and the meander. The authors claim that phase tunability of the meander line with the magnetodielectric perturber is much larger compared to traditional dielectric perturbers. The magnetodielectric perturber was manufactured using the self-biased NiCo-ferrite films. The Rogers material was used for the substrate.

Another switching phase shifter is presented in [30]. The size of phase shifter is 3 bits. The $0.18 \mu \mathrm{m}$ CMOS circuit technology is used for the manufacture. The miniaturization is achieved by using the meander conductors. The overall size of miniaturized chip of phase shifter is $0.57 \mathrm{~mm} \times 0.55 \mathrm{~mm}$. The $45^{\circ}, 90^{\circ}$ and $180^{\circ}$ phase shift is implemented. The measured average insertion loss was $11.8 \mathrm{~dB}$ at $24 \mathrm{GHz}$ with $0.9 \mathrm{~dB}$ variation. The maximum insertion loss was $16 \mathrm{~dB}$ at $29 \mathrm{GHz}$.

The achieved phase deviation and gain error were smaller than $5.3^{\circ}$ and $1.2 \mathrm{~dB}$ from $21 \mathrm{GHz}$ to $29 \mathrm{GHz}$. The meander structures were used in order to implement the inductors and allowed reducing the size of the entire circuit by $30 \%$. The most interesting fact is that the corners of the peripheral parts of connecting conductors are rounded. This is not an ordinary solution. Such a choice is not discussed in detail.

\section{E. Delay Lines with Meander Structures}

Delay line is another large group of devices, which have the meander structures in their construction [31], [32]. The W-band meander slow wave structure is presented in [33]. This structure is designed for the traveling wave tubes in order to work in the range of millimetre waves. The analysis has shown that it is possible to have the beam voltage until $10 \mathrm{kV}$ and beam current until $0.45 \mathrm{~A}$ using this type of tubes. The total length of the slow wave structure was $23 \mathrm{~mm}$ with loss of $0.1 \mathrm{~dB} / \mathrm{mm}$. The conventional structure of the meander line is used with the $90^{\circ}$ turns between central and connecting conductors.
Another example of the slow wave structure with the meander line is presented in [34]. This time the meander has the form of angular log-periodic micro-strip meander-line. The meander line is made from metal strip. The meander line and dielectric slab are shielded with the metal shield. Interesting form of a meander structure is given in [35]. This time the meander has a rhombus-shaped form. This form of meander has evolved from the V-shaped microstrip meander lines. The presented structure of meander is appropriate for the $140 \mathrm{GHz}$ traveling-wave tubes. The authors claim that the designed rhombus-shaped microstrip meander-line traveling wave tube is capable of delivering tens of watts of output power. S-type meander structure is presented in [36]. The S-type meander slow wave structure has some advantages in comparison with conventional meander slow wave structures. The central frequency is moved to higher frequencies. The transmission loss and coupling impedance are greatly improved in the high frequency range. The investigation of millimetre-wave tubes, which have the planar slow-wave structures, is presented in [37]. These structures are fabricated on dielectric substrates. The authors pay more attention to the fabrication of the meander structures and use traditional forms of meanders in this paper.

\section{$F$. Influence of Meander Shape}

An overview of applications of meander structures has shown that the shape of meander can vary a lot. The shape depends on the field of application and the desired parameters of operation. Many studies focus on the investigation of the influence of meander shape on performance.

The analysis of design of a meander conductor is presented in [38]. The analysis is oriented to increasing the withstand voltage of solid-state meander pulse forming line. The glass ceramic substrate was used for the manufacture. The investigation showed that a glass ceramic substrate allowed holding the voltage higher than $20 \mathrm{kV}$. The investigation also showed that the traditional form of meander had the edge effects on the field enhancement. Therefore, two new designs of meander conductor were investigated. First of all, the model of meander with the rounded connecting conductor was designed. Secondly, the dual parallel model of meander pulse forming line was simulated. The new designs of meander strips decreased the edge effect of the meander conductor.

Different parametric variations were studied in order to investigate the miniaturization possibilities of the proposed 2.5-D frequency selected surface in [39]. This surface was made using meander lines, which were orthogonally patterned on the opposite sides of the FR4 dielectric substrate. The current path was increased by using metallic vias, which connected the meander imprints. This construction resulted in a band stop response at $1.60 \mathrm{GHz}$ with compact unit cell size of $0.053 \lambda_{\mathrm{o}} \times$ $0.053 \lambda_{0}$.

The shape of the connecting conductor of meander has a considerable impact on the electromagnetic properties of the microwave devices. The meander line was used in [40] in order to increase the active area of the magnetoresistance sensor. The authors of the paper used many different structures of the meander conductor in order to get the required properties. The 
circular edge structure of the meander conductor allowed decreasing the coercive field to $37.5 \mathrm{Oe}$. The coercive field of rectangular edge was equal to $57.5 \mathrm{Oe}$.

\section{MODELS OF INVESTIGATION}

According to the review of the scientific literature, we have made two models of meander structures, which differ one from the other in the connecting conductors of the meander.

Meander structures are presented in the Sonnet software package (see Fig. 2). The traditional model of meander structure with the rectangular edges is presented in Fig. 2a. Different lengths and widths of the connecting conductor of the meander were used in the investigation. The meander structure with a triangular-shape connecting conductor is presented in Fig. $2 b$.

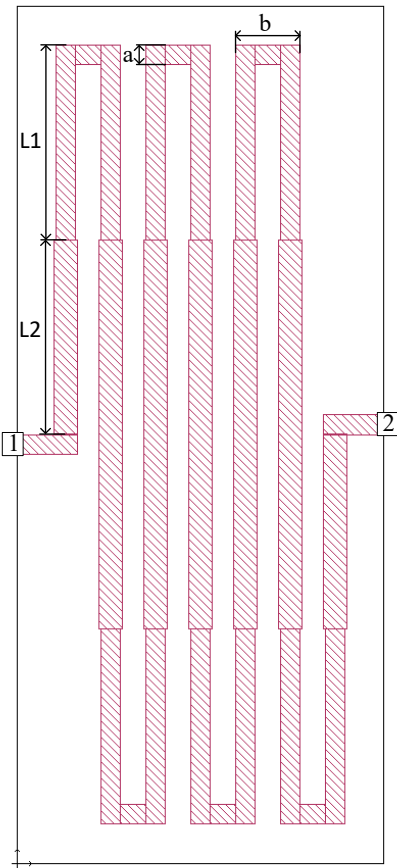

(a)

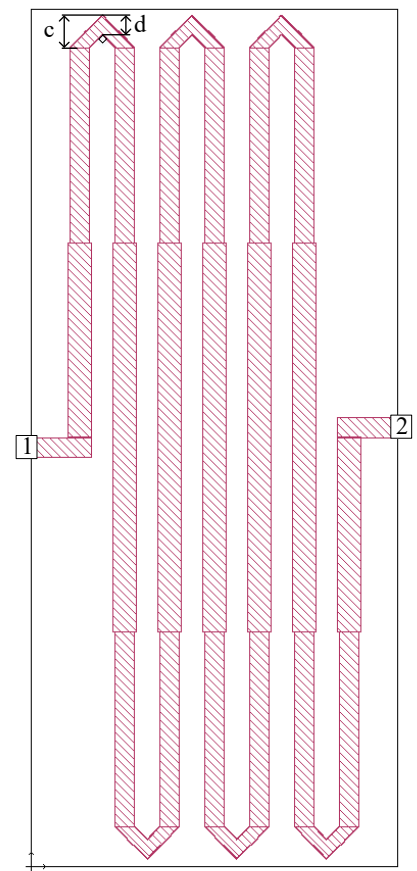

(b)
Fig. 2. The meander line models with (a) - traditional shape $\left(L_{1}=5 \mathrm{~mm}\right.$ $\left.L_{2}=5 \mathrm{~mm} ; a=0.5 \mathrm{~mm} ; b=1.65 \mathrm{~mm}\right),(\mathrm{b})$ - triangular-shaped $(c=0.825 \mathrm{~mm}$; $d=0.5 \mathrm{~mm}$; the angle $90^{\circ}$ ).

The length $b$ of the connecting conductor of the meander varied as long as the other parameters were kept the same during the first investigation. The width $a$ of the connecting conductor of the meander varied as long as the other parameters were constant during the second investigation. The triangle-shape edges were used in the connecting conductor of the meander during the third investigation.

The constant central meander strips were used in all models. The length of every central strip was equal to $20 \mathrm{~mm}$. The height of a dielectric substrate was equal to $0.5 \mathrm{~mm}$. The lossless materials were used in the investigation. The focus was on the structure of the meander conductor.

As a result of the analysis, the input impedance and frequency response or S21 parameters are presented.

\section{RESULTS}

Results of input impedance with the different width of the connecting conductor of the meander are presented in Fig. 3. The variation of width of the connecting conductor affects the input impedance of the meander system. The width of the connecting conductor of the meander varied from $0.2 \mathrm{~mm}$ to $1 \mathrm{~mm}$. The input impedance is quite similar in the frequency range from 0 to almost $2.827 \mathrm{GHz}$ and is equal to about $50 \Omega$. However, there is an extreme at $3.3 \mathrm{GHz}$.

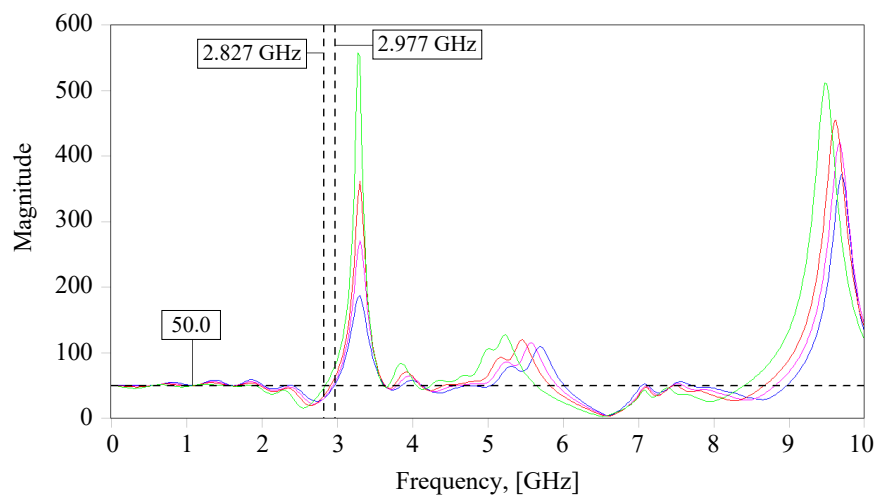

Fig. 3. Input impedance of the meander line, when $a=0.2 \mathrm{~mm}$ (blue); $a=0.4 \mathrm{~mm}$ (pink); $a=0.6 \mathrm{~mm}$ (red); $a=1 \mathrm{~mm}$ (green); $Z_{0}=50 \Omega$.

Larger width of the connecting conductor of the meander causes bigger values of extremes of input impedance. The extreme starts earlier when the width of the connecting conductor is bigger. The input impedance changes by several hundred ohms in the range of $a$ parameter from $0.2 \mathrm{~mm}$ to $1 \mathrm{~mm}$. The parameter of input impedance is useful for analysing system stability.

It could be seen from the S21 parameter that the width of the connecting conductor of meander influences the occurrence of a stop-band at specific frequencies (Fig. 4). Larger width of the connecting conductor causes a narrower pass-band of the meander line. The stopband starts earlier at $2.338 \mathrm{GHz}$ when the width is equal to $1 \mathrm{~mm}$. The passband decreases by $346 \mathrm{MHz}$.

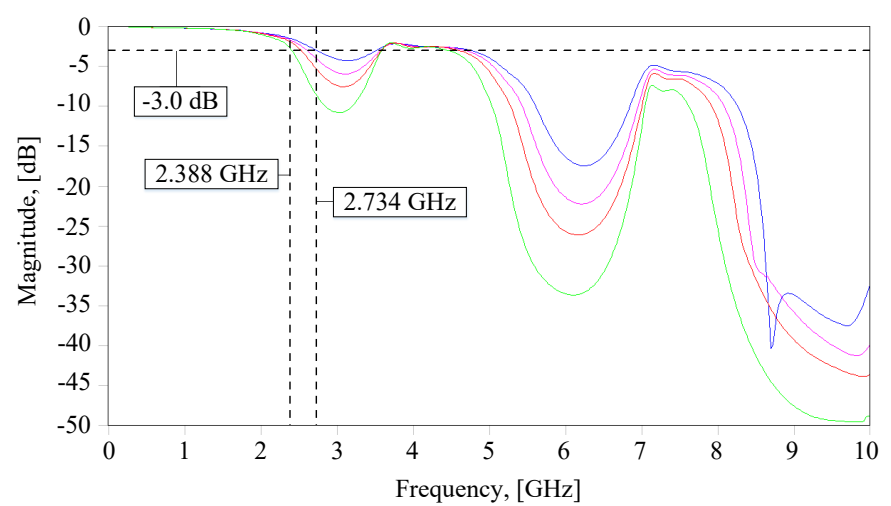

Fig. 4. Magnitude frequency response of the meander line, when $a=0.2 \mathrm{~mm}$ (blue); $a=0.4 \mathrm{~mm}$ (pink); $a=0.6 \mathrm{~mm}$ (red); $a=1 \mathrm{~mm}$ (green); $Z_{0}=50 \Omega$.

Such a decrease in bandwidth could be attributed to the physical properties of the meander line. Increasing width of the 
conductor increases the unit capacity of the line length and decreases the wave impedance of the connecting conductor of the meander line. Periodic irregularities of the meander line become apparent. Periodic irregularities lead to the formation of a stopband and the emergence of a passband.

The next study was performed by varying the length of the connecting conductor of the meander. In other words, the width of the gap between the central meander strips was changed while keeping all other parameters of the meander line constant.

The increase in the length of the connecting conductor of the meander affects the decrease in the extreme of the input impedance. On the other hand, all extremes start almost at the same time using all different lengths of the connecting conductor of the meander (Fig. 5).

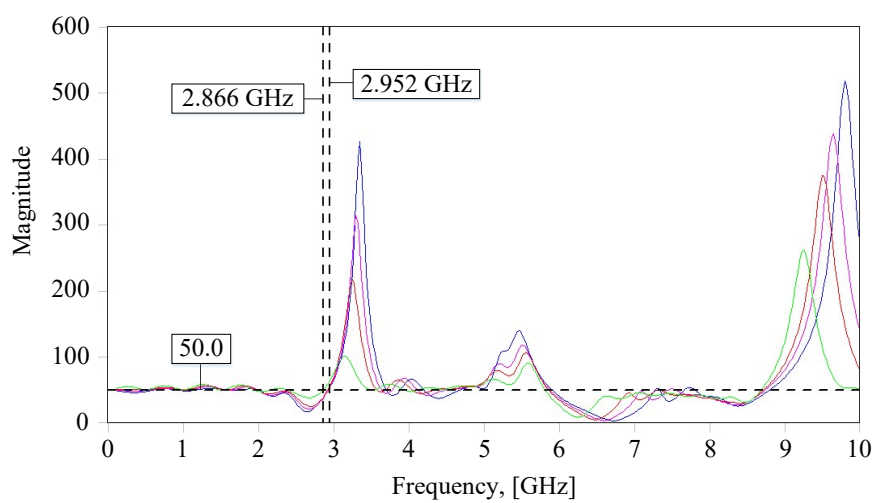

Fig. 5. Input impedance of the meander line, when $b=1.45 \mathrm{~mm}$ (blue); $b=1.65$ $\mathrm{mm}$ (pink); $b=1.85 \mathrm{~mm}$ (red); $b=2.3 \mathrm{~mm}$ (green); $Z_{0}=50 \Omega$.

The influence of the adjacent strips of the central part of the meander conductor on each other decreases when the distance between the adjacent strips increases (Fig. 6).

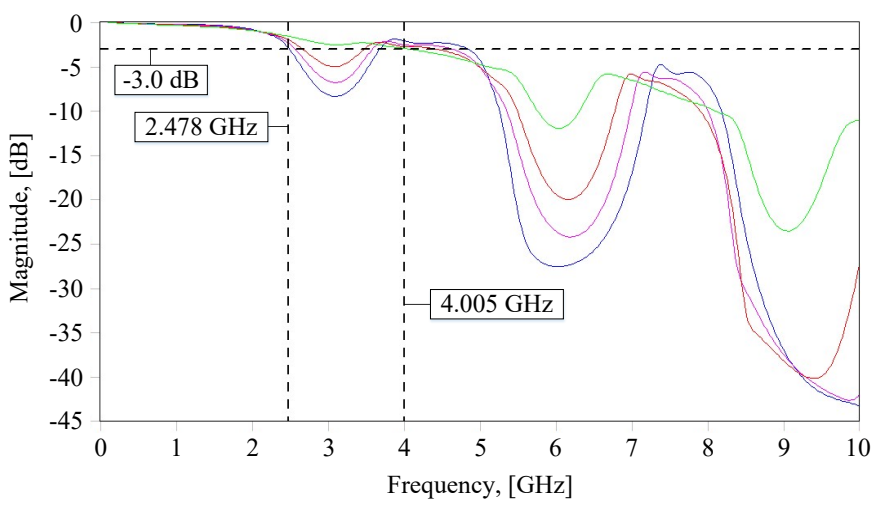

Fig. 6. Magnitude frequency response of the meander line, when $b=1.45 \mathrm{~mm}$ (blue); $b=1.65 \mathrm{~mm}$ (pink); $b=1.85 \mathrm{~mm}$ (red); $b=2.3 \mathrm{~mm}$ (green); $Z_{0}=50 \Omega$.

In other words, the capacity of the unit of length decreases. The periodic variation of the wave resistance then also decreases and the barrier band at $3.3 \mathrm{GHz}$ disappears. The bandwidth extends up to $4 \mathrm{GHz}$. The influence of the capacitance increases at higher frequencies. Therefore, the barrier stopband is formed at $6 \mathrm{GHz}$ when the length of the connecting conductor of the meander is equal to $2.3 \mathrm{~mm}$.
The comparison of the traditional model of the meander conductor and the meander conductor with triangle-shaped connecting conductors is presented in Figs. 7 and 8. The model with triangle-shape connecting conductors allows decreasing the dispersion of input impedance and the extreme of input impedance is lower (Fig. 7). The difference of input impedance is about $70 \Omega$.

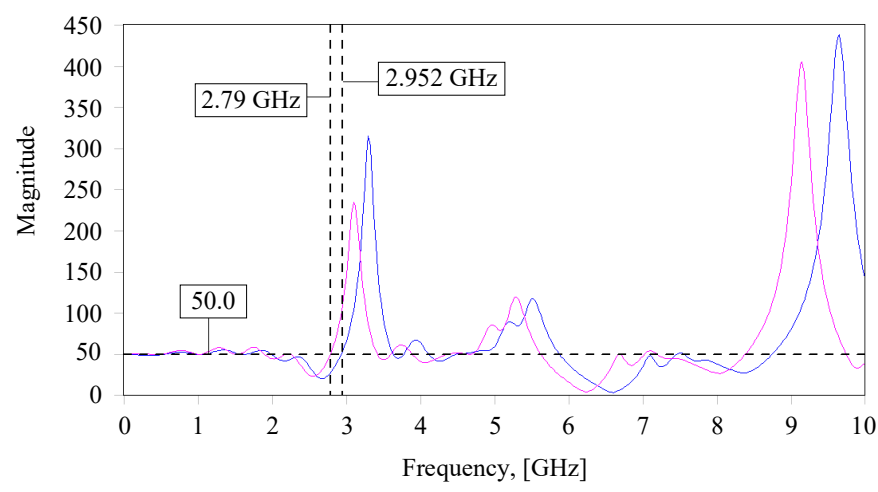

Fig. 7. The comparison of input impedance of the traditional (blue) and triangleshaped (pink) meander lines, when $Z_{0}=50 \Omega$.

On the other hand, the stopband of the model with triangleshape connecting conductor starts about $76 \mathrm{MHz}$ earlier (Fig. 8).

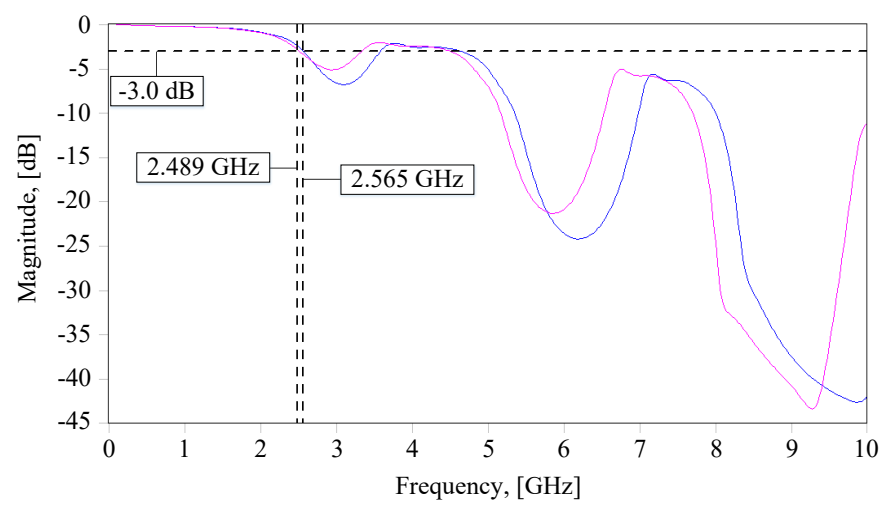

Fig. 8. Comparison of magnitude frequency response of the traditional (blue) and triangle-shaped (pink) meander lines, when $Z_{0}=50 \Omega$.

Hence, it is possible to have more stable performance but with a lower bandwidth by applying the meander with a triangle-shape connecting conductor.

\section{CONCLUSION}

The review of different structures of meander conductors has been presented. The shape of connecting conductors of the meander has a significant impact on the electrodynamic characteristics (passband and stopband, width of the operational bands, dispersion of frequency characteristics) of the entire microwave devices.

Two models of meander lines have been investigated. The change in the length or width of the connecting conductor of the meander has a significant impact on the operation of the meander line. The increase in the width of the connecting 
conductor of the meander causes the decrease in the bandwidth. The increase in the length of the connecting conductor of the meander moves the stopband to higher frequencies. The usage of the meander conductor with triangle shape almost did not affect the bandwidth, but allowed decreasing the dispersion of input impedance.

\section{REFERENCES}

[1] N. Othman, N. A. Samsuri, M. K. A. Rahim and K. Kamardin, "Transmission Characteristic of Meandered Bowtie Antenna at $2.4 \mathrm{GHz}$ in Proximity to Human Body," IEEE Asia-Pacific Conference on Antennas and Propagation, Auckland, 2018, pp. 405-406. https://doi.org/10.1109/APCAP.2018.8538146

[2] M. Podamekala, A. R. L. Prathyusha, S. Mamidi and P. Verma, "Design of a Meandered Line Microstrip Patch Antenna with Array Implementation," International Conference on Wireless Communications Signal Processing and Networking, Chennai, India, 2019, pp. 1-3. https://doi.org/10.1109/WiSPNET45539.2019.9032877

[3] P. Zhou, Y. Shi and W. Tang, "Multi-Mode and Ultra-Wideband Common-Mode Filter Based on Asymmetric Short-Stub Loaded Resonator," IEEE MTT-S International Wireless Symposium (IWS), Guangzhou, China, 2019, pp. 1-3. https://doi.org/10.1109/IEEEIWS.2019.8804095

[4] J. Yoo, S. Khang, T. Yeo and J. Yu, "Compact Meander Magnetic Dipole Antenna for Wide-Angle Scanning," IEEE International Symposium on Antennas and Propagation \& USNC/URSI National Radio Science Meeting, Boston, 2018, pp. 1611-1612.

https://doi.org/10.1109/APUSNCURSINRSM.2018.8608380

[5] A. B. Varuna, S. Ghosh, H. Sheokand and K. V. Srivastava, "A polarization-insensitive miniaturized element frequency selective surface using meander lines," Twenty Fourth National Conference on Communications, Hyderabad, 2018, pp. 1-4. https://doi.org/10.1109/NCC.2018.8600227

[6] M. Yamaguchi, K. Cho, T. Yoshihara, T. Ihara, "Application of Choke Element to Dual-Band Reflector Backed Dipole Antenna Loading Meander-Loop Parasitic Element," IEEE International Workshop on Electromagnetics: Applications and Student Innovation Competition, 2018. https://doi.org/10.1109/iWEM.2018.8536711

[7] S. Zhang, J. Ouyang, Y. Yan, L. Zhuang and J. Guo, "A Novel Meander Line RFID Reader Antenna for UHF Near-Field Applications," IEEE International Symposium on Antennas and Propagation \& USNC/URSI National Radio Science Meeting, Boston, 2018, pp. 1297-1298. https://doi.org/10.1109/APUSNCURSINRSM.2018.8608744

[8] M. G. N. Alsath, M. Kanagasabai and B. Balasubramanian, "Implementation of Slotted Meander-Line Resonators for Isolation Enhancement in Microstrip Patch Antenna Arrays," IEEE Antennas and Wireless Propagation Letters, 2013, vol. 12, no. 1, pp. 15-18. https://doi.org/10.1109/LAWP.2012.2237156

[9] Z. Chen, M. Tang, Y. Wang, M. Li and D. Li, "Mutual Coupling Reduction Using Planar Parasitic Resonators for Wideband, DualPolarized, High-Density Patch Arrays," IEEE MTT-S International Wireless Symposium, Guangzhou, China, 2019, pp. 1-3. https://doi.org/10.1109/IEEE-IWS.2019.8803886

[10] J. Shu, H. Peng, Y. Zhang and J. Mao, "A Dual Polarized Pattern Reconfigurable Antenna Array Using Liquid Crystal Phase Shifter," International Symposium on Antennas and Propagation (ISAP), Busan, Korea (South), 2018, pp. 1-2.

[11] H. Al-Saedi, S. Gigoyan, W. M. Abdel-Wahab, A. Palizban and S. SafaviNaeini, "A Continuous $2 \pi$ Phase Shifter for Ka-Band Applications," 48th European Microwave Conference (EuMC), Madrid, 2018, pp. 10251028. https://doi.org/10.23919/EuMC.2018.8541593

[12] Z. J. Hou, Q. Xue, Y. Yang, X. Zhu and E. Dutkiewicz, "Miniaturized millimeter-wave on-chip bandpass filter design in $0.13-\mu \mathrm{m}$ SiGe BiCMOS technology," 17th International Symposium on Communications and Information Technologies, Cairns, 2017, pp. 1-5. https://doi.org/10.1109/ISCIT.2017.8261220

[13] C. Karpuz, A. Gorur, E. Sahin, "Dual-mode dual-band microstrip bandpass filter with controllable center frequency," Microwave and Optical Technology Letters, vol. 57, no. 3, 2015, pp. 639-642. https://doi.org/10.1002/mop.28914
[14] S. K. Podilchak, J. C. Johnstone, M. Caillet, M. Clénet and Y. M. M. Antar, "A Compact Wideband Dielectric Resonator Antenna With A Meandered Slot Ring and Cavity Backing," IEEE Antennas and Wireless Propagation Letters, 2016, vol. 15, pp. 909-913. https://doi.org/10.1109/LAWP.2015.2480547

[15] S. Chakraborty, Y. Yang, X. Zhu, O. Sevimli, Q. Xue, K. Esselle, M. Heimlich, "A Broadside-Coupled Meander-Line Resonator in 0.13- $\mu \mathrm{m}$ SiGe Technology for Millimeter-Wave Application," IEEE Electron Device Letters, 2016, vol. 37, no. 3, pp. 329-332. https://doi.org/10.1109/LED.2016.2520960

[16] W. Hui and S. Li, "New Design of Delay Line Based on Slow-Wave Structure," 4th International Conference on Information Science and Control Engineering (ICISCE), Changsha, 2017, pp. 1556-1558. https://doi.org/10.1109/ICISCE.2017.324

[17] K. Salim, S. Roman and N. Alexander, "Propagation of pulse signals in the turn of a meander microstrip delay line," International MultiConference on Engineering, Computer and Information Sciences (SIBIRCON), 2019, pp. 254-257.

[18] M. S. Islam, M. T. Islam, M. A. Ullah, G. K. Beng, N. Amin and N. Misran, "A Modified Meander Line Microstrip Patch Antenna With Enhanced Bandwidth for $2.4 \mathrm{GHz}$ ISM-Band Internet Of Things (IoT) Applications," IEEE Access, 2019, vol. 7, no. 1, pp. 127850-127861. https://doi.org/10.1109/ACCESS.2019.2940049

[19] H. M. Santos, P. Pinho, R. P. Silva, M. Pinheiro and H. M. Salgado, "Meander-Line Monopole Antenna With Compact Ground Plane for a Bluetooth System-In-Package," IEEE Antennas and Wireless Propagation Letters, 2019, vol. 18, no. 11, pp. 2379-2383. https://doi.org/10.1109/LAWP.2019.2927467

[20] I. T. E. Elfergani, A. S. Hussaini, J. Rodriguez and R. A. Abd-Alhameed, "Miniaturized dual-band balanced antenna for LTE using meander lines," 13th International Conference on Synthesis, Modeling, Analysis and Simulation Methods and Applications to Circuit Design, 27-30 June, 2016, Lisbon, Portugal. https://doi.org/10.1109/SMACD.2016.7520733

[21] X. Fang, G. Wen, D. Inserra, Y. Huang and J. Li, "Compact Wideband CPW-Fed Meandered-Slot Antenna With Slotted Y-Shaped Central Element for Wi-Fi, WiMAX, and 5G Applications," IEEE Transactions on Antennas and Propagation, 2018, vol. 66, no. 12, pp. 7395-7399. https://doi.org/10.1109/TAP.2018.2869254

[22] K. K. Naik, and M. H. V. Manikanta, "Design of Circular Slot on Rectangular Patch With Meander Line Antenna for Satellite Communications," Proceedings of the 2nd International Conference on Inventive Communication and Computational Technologies, 2018. pp. 1252-1255. https://doi.org/10.1109/ICICCT.2018.8473217

[23] S. Bhole, A. Rathod, S. Doddipalli, S. Kannaiyan and A. Kothari, "A Compact Planar Antenna With Meander Lines for TV White Space Applications," IEEE International Students Conference on Electrical, Electronics and Computer Science, Bhopal, 2018, pp. 1-4. https://doi.org/10.1109/SCEECS.2018.8546913

[24] R. Kazemi, J. Palmer, F. Quaiyum and A. E. Fathy, "Steerable miniaturised printed quadrifilar helical array antenna using digital phase shifters for BGAN/GPS applications," IET Microwaves, Antennas \& Propagation, vol. 12, no. 7, 2018, pp. 1196-1204. https://doi.org/10.1049/iet-map.2017.0959

[25] X. Tan, W. Wang, Y. Wu, Y. Liu and A. A. Kishk, "Enhancing Isolation in Dual-Band Meander-Line Multiple Antenna by Employing Split EBG Structure," IEEE Transactions on Antennas and Propagation, 2019, vol. 67 , no. 4, pp. $2769-2774$. https://doi.org/10.1109/TAP.2019.2897489

[26] P. H. Mukti, H. Schreiber, A. Gruber, H. Paulitsch and W. Bösch, "Numerical analysis of meandered line based uniform antenna array," 11th German Microwave Conference (GeMiC), Freiburg, 2018, pp. 215218. https://doi.org/10.23919/GEMIC.2018.8335068

[27] Y. Zhong, Y. Yang, X. Zhu, E. Dutkiewicz, K. M. Shum and Q. Xue, "An On-Chip Bandpass Filter Using A Broadside-Coupled Meander Line Resonator With a Defected-Ground Structure," IEEE Electron Device Letters, vol. 38, no. 5, pp. 626-629, 2017. https://doi.org/10.1109/LED.2017.2690283

[28] A. J. Salim, S. A. Gitaffa, M. S. Taha and J. K. Ali, "A Dual-Band BPF Based on Asymmetrical-Meandered Configuration for Communication Systems," Third Scientific Conference of Electrical Engineering (SCEE), Baghdad, Iraq, 2018, pp. 294-298. https://doi.org/10.1109/SCEE.2018.8684156 
[29] G.-M. Yang, J. Lou, O. Obi and N. X. Sun, "Novel compact and low-loss phase shifters with magnetodielectric disturber," IEEE Microwave and Wireless Components Letters, 2011, vol. 21, no. 5, pp. 240-242. https://doi.org/10.1109/LMWC.2011.2123085

[30] W. Tseng, C. Lin, Z.-M. Tsai and H. Wang, "A miniature switching phase shifter in 0.18- $\mu \mathrm{m}$ CMOS," 2009 Asia Pacific Microwave Conference, Singapore, 2009, pp. 2132-2135.

https://doi.org/10.1109/APMC.2009.5385505

[31] A. Nosov, R. Surovtsev, T. Gazizov, "Propagation of UWB pulse in two turns of meander microstrip line connected in cascade," 2019 International Multi-Conference on Engineering, Computer and Information Sciences, 2019, pp. 288-292.

https://doi.org/10.1109/SIBIRCON48586.2019.8958349

[32] S. Lee, J. Lim, S. Oh and J. Lee, "Common-mode conversion noise mitigation with embedded coupled lines in differential serpentine delay microstrip lines," IEEE Transactions on Electromagnetic Compatibility, 2020, pp. 1-9. https://doi.org/10.1109/TEMC.2020.2975831

[33] M. Sumathy, L. Christie, S. K. Datta and L. Kumar, "Analysis of a W-band meander-line slow-wave structure for millimeter-wave travelingwave tubes," IVEC 2012, Monterey, 2012, pp. 461-462. https://doi.org/10.1109/IVEC.2012.6262240

[34] S. Wang, Z. Cao, Y. Hou, G. Zhao, Y. Wei, Z. Duan, Z. Wang, Y. Gong, "A novel angular log-periodic micro-strip meander-line slow wave structure for low-voltage and wideband traveling wave tube," IEEE 14th International Vacuum Electronics Conference (IVEC), Paris, 2013, pp. 12. https://doi.org/10.1109/IVEC.2013.6571028

[35] F. Shen, W. Wei, X. Yanyu, L. Xiong, H. Jianqiang, M. Huang, G. Zhao and Y. Gon, "Rhombus-shaped microstrip meander-line slow-wave structure for $140 \mathrm{GHz}$ traveling-wave tubes," IEEE 13th International Vacuum Electronics Conference, IVEC, 2012, pp. 389-390. https://doi.org/10.1109/IVEC.2012.6262206

[36] N. Bai, L. Gu, C. Shen, J. Feng, F. Liao and X. Sun, "S-shaped microstrip meander-line slow-wave structure for W-band traveling-wave tube," IEEE 14th International Vacuum Electronics Conference (IVEC), Paris, 2013, pp. 1-2. https://doi.org/10.1109/IVEC.2013.6571098

[37] N. M. Ryskin, A. I. Benedik, A. G. Rozhnev, N. I. Sinitsyn, R. A Torgashov and G. V. Torgashov, "Study of low-voltage millimeter-wave tubes with planar slow-wave structures on dielectric substrates," 10th UKEurope-China Workshop on Millimetre Waves and Terahertz Technologies (UCMMT), Liverpool, 2017, pp. 1-2. https://doi.org/10.1109/UCMMT.2017.8068463

[38] L. Wang, J. Liu and Q. Zhang, "Analysis of the electrode design to increase the withstand voltage of solid state meander pulse-forming line," IEEE Transactions on Dielectrics and Electrical Insulation, 2016, vol. 23 , no. 6, pp. 3443-3449. https://doi.org/10.1109/TDEI.2016.005746

[39] S. Ghosh, "Miniaturized-element frequency selective surface based on 2.5-Dimensional meander lines," IEEE Asia-Pacific Microwave Conference (APMC), Singapore, Singapore, 2019, pp. 850-852. https://doi.org/10.1109/APMC46564.2019.9038865

[40] Y. H. Chan, M. J. Chen, J. J. Chiang, I. C. Liao, T. H. Wu, C. M. Lee, W. Y. Peng, J. Y. Chen, J. Y. Lai, C. K. Lo, Z. H. Wei, "Edge effect on coercive field of GMR sensors with meander line structure," IEEE Transactions on Magnetics, 2014, vol. 50, no. 1, pp. 1-4. https://doi.org/10.1109/TMAG.2013.2273453

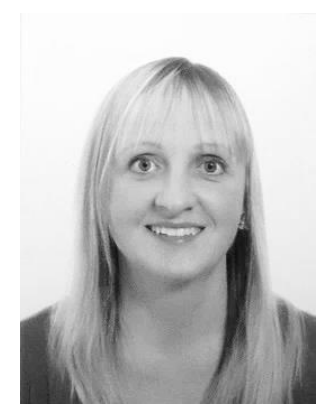

Diana Belova-Plonienè obtained her B. sc. and M. sc. degrees in Electronic Engineering from Vilnius Gediminas Technical University in 2009 and 2011, respectively.

Currently, she is a Doctoral student and works as a Specialist at Vilnius Gediminas Technical University, Vilnius, Lithuania. Her research interests include the electromagnetic field theory, super-high frequency technologies, microwave devices and signal processing.

Address: Vilnius Gediminas Technical University, Faculty of Electronics, Naugarduko Str. 41 - 423, Vilnius, LT-03227, Lithuania.

E-mail: d.belova-ploniene@vgtu.lt

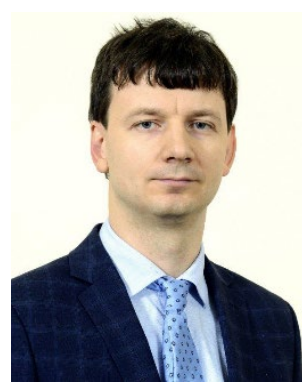

Andrius Katkevičius obtained his B. sc., M. sc. and doctoral degrees in Electrical and Electronic Engineering from Vilnius Gediminas Technical University in 2007, 2009, and 2013, respectively. In 2017, he received the title of Associate Professor at VGTU.

$\mathrm{He}$ is a Professor at the Department of Electronic Systems of Vilnius Gediminas Technical University. His main research interests include the electromagnetic field theory, super-high frequency technologies and microwave devices, signal processing, multimedia and embedded

systems

Address: Vilnius Gediminas Technical University, Faculty of Electronics, Naugarduko Str. 41 - 415, Vilnius, LT- LT-03227, Lithuania.

E-mail: andrius.katkevicius@,vgtu.lt

ORCID iD: https://orcid.org/0000-0002-1623-5643 